\title{
Governing Restoration: Strategies, adaptations and innovations for tomorrow's forest landscapes
}

Governance structures are urgently needed to promote forest landscape restoration (FLR). In light of recent commitments to mitigate climate change and conserve biodiversity, international organizations are calling for vast areas of land to be restored over the next few decades. At the landscape level, for restoration to be adopted and sustained, it must be attractive to multiple stakeholders with diverse goals that unfold over different spatial and temporal scales. Thus, restoring forest landscapes inherently involves interactions between many levels and types of organizations, institutions, and stakeholders. As a global paradigm, FLR is a relatively new idea, and governance structures required to facilitate and sustain it over time are not obvious. But fortunately, examples of successfully governing FLR can be found in different contexts around the world, with lessons for restoration efforts elsewhere. In this paper, we summarize the differences and similarities between FLR and previous interventions (ecological restoration, forest conservation, and so on) and the specific governance challenges it presents. We then provide an overview of case reports illustrating innovative governance structures that have contributed to successful FLR, presented in this special section in the journal World Development Perspectives. Cases at the local, national, and multinational levels include new governance institutions or arrangements that have supported landscape restoration in a given context, and the innovative use of existing governance structures to produce landscape-level forest restoration. Collectively, these cases demonstrate that successful governance approaches should be people-centered, adaptable to local contexts and needs, engage a range of stakeholders across different scales and sectors, and be flexible enough to incorporate local practices and ideas. These cases present a range of different models and techniques for achieving this. 


\section{Key words}

Forest landscape restoration; ecological restoration; forest conservation; governance; natural resource management; community forestry.

\section{Introduction}

A major challenge for the $21^{\text {st }}$ century is restoring and rehabilitating cleared and degraded land. Vast areas of land have been converted to other land uses (Foley et al. 2007, Lewis et al. 2015) and an estimated 1 billion people now live in degraded areas, more than $15 \%$ of the world's population (Sabogal et al. 2015). This poses major environmental and social problems, including decreased biodiversity and ecosystem services, increased competition for land, and in some cases high levels of outmigration from rural areas (Foley et al. 2005, Hecht et al. 2015). Combined with an unprecedented interest in improved land use practices and reforestation to mitigate climate change - forests and restoration received more attention than ever before at the COP 21 meeting in Paris, 2015 - these issues have governments and agencies calling for vast areas of degraded land to be restored immediately.

The strategic plan of the United Nations Convention on Biological Diversity for 20112020 aims to restore $15 \%$ of all degraded lands by 2020 , a target consistent with the 150 million hectares set by the Bonn Challenge and the New York Declaration on Forests. In certain areas, some of these forests are likely to return 'passively' as countries or regions urbanize, and people abandon marginal farmland suitable for forest regrowth (Rudel et al. 2005, Chazdon 2015). But in areas where land is severely degraded or still under use, active restoration, which consists of encouraging forest regrowth through a variety of interventions (including tree planting, assisted regeneration, and so on) will be required (Chazdon 2008). This large-scale restoration requires coordinating efforts across landscapes and stakeholders at many levels. 
These unprecedented global restoration goals thus present challenges, opportunities, and questions: First, for whom are we restoring, and to what end? Active restoration can take many forms, and achieve many different end goals depending on how it is designed, implemented and managed. Farm forestry, agroforestry, social forestry, smallholder plantations and ecological restoration efforts can all be considered forms of active reforestation that meet different goals for end users, and may be more or less appropriate in different contexts. Second, how are we to restore ecosystems at such large scales? The answer to this question is simultaneously technical (by what cost effective means can we encourage forests to grow back on degraded lands?); economic (who pays for this restoration, and why?); political (what policies can best support restoration?); and cultural (what are the values, norms and behaviours that promote and sustain restoration? Why would people want to restore forests, in their locale or remotely?). Addressing all of these aspects is critical for the success of such initiatives, and requires researchers, policy makers and practitioners to work together: to look to both the past and future, adapt current models and tools to fit the new demands and challenges that global restoration targets present, and build and design new and forward-thinking strategies. We propose that governance is a central and important component of any such strategy, influencing the who, what, where, when, how, and why.

In this special issue, we present a collection of case reports identifying governance models that support and foster restoration at multiple scales, from household to international levels. These examples will directly feed into global restoration efforts by providing current, robust, and context-specific examples of innovative strategies that have worked, or hold promise, to promote forest restoration at the landscape scale. Success stories are complemented by arrangements designed to produce these results that fell short of the mark. Presenting and 
synthesizing these experiences will, we hope, help policy makers and practitioners at all levels produce reforestation strategies that work for both people and forests.

\section{Forest landscape restoration (FLR): Novelty, goals and challenges}

Restoring landscapes at large scales will inevitably involve working with people. Unlike conservation areas that can be tucked away in relatively uninhabited lands (Joppa and Pfaff 2009), restoration will often involve actively restoring areas currently (or recently) in use, including some that are densely populated. Past restoration efforts have, with some notable exceptions, focused on restoring relatively small areas of land. Ecological restoration typically focuses at the scale of the ecosystem or patch with the intention of helping it to recover both structure and function, with an emphasis on maintaining historical fidelity (SER 2004). But the problems with 'scaling up' these efforts to meet current restoration goals are numerous. For example, when considering only the ecosystem or stand level, it is difficult to guarantee that restoring a patch of forest will not displace the previous land use elsewhere, at the expense of other forest (which may be primary forest, and thus more ecologically valuable) (Sloan 2008, Dent and Wright 2009). In addition, although production, cultural and aesthetic goals may be taken into account when designing an ecological restoration project, it is difficult to achieve a wide spectrum of both social and ecological goals when the focus of restoration is on restoring a single ecosystem. The scale or scope of ecological restoration projects is often relatively small by necessity, in part because of the costs and labor required in the start-up and maintenance/monitoring phases, and in part because degraded ecosystems requiring restoration are often found in inhabited landscapes where people are still using the land. To restore larger areas, a comprehensive strategy must thus include conserving existing forests, allowing them to 
regenerate where they can, planting them where they cannot, and managing their use to allow the people inhabiting these landscapes to produce food and otherwise pursue a meaningful livelihood. Restoration at the landscape scale allows for spatial heterogeneity to account for different social and ecological goals through strategic landscape design. Coordinating these efforts will require forward-thinking strategies that bring together people and organizations across scales, economic interests, and socioeconomic groups.

This is exactly what Forest Landscape Restoration (FLR) aims to achieve. FLR was conceived of by international governance bodies interested in improving degraded land to meet both social and ecological goals. An active process, FLR aims to bring people together to grow trees and forests. Compared to past restoration efforts, FLR is considerably more complex as it aims to encompass and coordinate multiple land uses, of which ecological forest restoration is one. When compared to ecological restoration, people play a much larger role - improving livelihoods, well-being, and food security are top priorities, as well as restoring ecological structure, function and processes (Chazdon et al. in prep, Laestadius et al. 2015). Thus, FLR also incorporates and includes diverse forms of active reforestation, which are broader and less focused on ecological integrity than ecological restoration, including agroforestry, small woodlots, and other methods of incorporating trees into the landscape that are not strictly intended to produce a 'native' forest (Chazdon et al. 2016). These 'forests for people' may include more exotic species, different proportions of species from native forests, integrate annual crops and livestock, and may also be subject to cyclical harvesting cycles (Bhagwat et al. 2007, De Beenhouwer et al. 2013).

Forest landscape restoration directly addresses the issue of 'leakage' that can be problematic with ecological restoration. By taking a holistic view of the landscape, it is possible 
to both accommodate production and ecological goals while allowing managers to address the question "when you restore a patch here, what happens there?" Planting or aiding forest recovery in different ways and different locations to meet different needs allows for a wider range of interventions, and thus more potential avenues through which to promote trees and forests on the landscape (Sabolgal 2015). Different treed 'niches' can fulfil different goals, and may be practiced by landholders with a wide range of livelihood objectives (Wilson 2015). However, a major critique of FLR is its treatment of trees and forest - to achieve both social and ecological goals, it broadly defines the way that forests and trees can be incorporated into ecosystems, which has some ecologists concerned that ecological robustness will be compromised.

Forest landscape restoration is intended to be a collaborative process, involving multiple stakeholder groups and, ideally, consensus decision making. This is possible (at least in theory) because it allows for this range of interventions for different purposes. In practice, however, this can be extremely challenging as 'landscape' is typically not a jurisdictional unit, and managing them requires coordinating different levels of government, local residents and other local stakeholders, and in some cases international bodies interested in funding restoration. This type of collaboration is often called for to solve complex environmental problems (for example, consider the Paris Climate Agreement) but in practice is exceedingly difficult to achieve. Governance structures that can produce such arrangements are thus urgently needed, and with restoration such a recent component of global agendas, it is critical that we identify governance mechanisms that can support the multifaceted action required to restore landscapes.

Although FLR and its associated goals are a relatively new concept, the practice of managing landscapes to achieve multiple ecological and social goals is not. Examples exist of governance mechanisms that have attempted to achieve this with varying degrees of success; 
thus, despite some differences in goals and processes, it is worth reflecting on past efforts to govern forests and landscapes for conservation as we move forward with restoration. What governance approaches have been tried? How have they played out on the ground? Can they be made to work for restoration, or, do we need completely new approaches?

\section{Approaches to governing conservation: past and present}

\section{Participation and decentralization}

Forests have been used and managed by humans throughout history. The current state of forests and the ways in which they are governed has been shaped by major trends in forest conservation over the last century. Early models of state-led forest conservation were based on a belief that people and 'use' are a threat to forests. Conservation, therefore, required carefully managing forests to sustain them as a crop to be harvested, and protecting them from overexploitation. Globally, governments began creating reserves and national parks, which required displacing people and enclosing protected areas to keep people out (Neumann 2004).

By the 1970s, prompted in large part by the emerging discourse on Sustainable Development, critiques of social injustice, and the cost inefficiencies and poor performance associated with enclosured protected areas, a major shift began towards people-centered approaches marked by participation and decentralization (Chazdon et al. 2016). However, early people-centered approaches still perceived people as forest destroyers. The dominant conservation approach was implementing projects that aimed to reduce human pressure and impact on forests by offering incentives to cease or restrict forest use, such as alternative sources of forest goods, income, or other compensation - an approach commonly used in "integrated conservation and development projects". Requirements for successful governance under this 
approach included community cooperation, long-term funding, and effective enforcement (Alpert 1995).

In the 1980s, international governing bodies embraced a new characterization of communities as long-standing forest stewards. This paradigm shift prompted governance approaches centered on increasing community participation, rights, and responsibilities for forest management. Broadly framed as decentralization, this includes a shift in power away from the central state to local communities, though in practice this shift has rarely been realized and, instead has produced positive results in some cases (e.g., increased empowerment, income, and access to resources) but negative ones in others (e.g., elite capture and local conflict, increased vulnerability of local users to government regulations, increased responsibility for management without increased benefit from the resource, local institutions being undermined, no empowerment in decision-making, involvement only as paid labor, and new forms of exclusion by privatization). Improved democratic governance mechanisms could contribute to more successful and real decentralization, including having representative authorities to speak on behalf of local user populations and improving accountability from these decision-makers to local communities, or giving real decision-making power and access to resources to local communities (Ribot 2004).

Land tenure is one of the primary governance mechanisms in the community-based approach to conservation. In this context, land tenure can include ownership, user rights and responsibilities, the enforcement of property rights, or all three. Though most forests world-wide are state-owned, more than one fourth of forests in developing countries are either owned by or managed by communities (Larson et al. 2010). Tenure reforms have often involved transferring or recognizing the rights of communities occupying forestlands, including indigenous rights, 
along with responsibilities to protect forests. However, in most cases the state has retained management rights and control (Larson et al. 2010). As a result, giving communities land tenure rights has simultaneously expanded and restricted their power by, on one hand, increasing legal rights to forest resources (typically subsistence rights), but, on the other, undermining local institutions with increased state control, monitoring, and regulation. The most effective decentralized governance has been found to be that which improves both access and exclusion rights, and also decision-making rights (Larson et al. 2010).

\section{Market-based approaches}

In response to underperforming past conservation efforts, alternative market-based approaches were put forth. The rationalization for market-based approaches is that the financial investments made in previous conservation approaches are indirect, with limited environmental and livelihood benefits despite huge sums of money spent, but that direct payments for conservation would produce greater conservation and livelihood impacts (Nicholls 2004). Ecosystem services gained major attention at the beginning of this century with the Millennium Ecosystem Assessment (MEA) which presents a framework for understanding their value and contributions to human well-being (2005). The ecosystem services framework for conservation is complex because ecosystem goods and services vary widely over temporal and spatial scales, have a wide range institutional arrangements governing them, and involve a diverse mix of stakeholders in different settings (Turner and Daily 2008). Despite this complexity, payment for ecosystem services (PES) schemes have been increasingly implemented over the past decade. In PES schemes, land user 'sellers' are paid to provide defined ecosystem service(s) to 'buyers,' and participation is voluntary. The approach works best where ecosystems are moderately threatened, and therefore there are moderate (i.e., not prohibitive) conservation opportunity costs 
but demonstrated conservation benefits. Proponents of PES schemes argue that they are more cost-efficient than indirect approaches (Wunder 2007), and have the possibility to increase conservation funding while reducing the responsibility on governments (Pattanayak et al. 2010). However, PES schemes require the value of ecosystem service to be quantified to set market prices, a very complex and challenging task from both ecological and economic perspectives (Kinzig et al. 2011). The most well-known PES arrangement may be Reducing Emissions from Deforestation and Forest Degradation (REDD+), a global scale scheme to reduce carbon emissions and mitigate climate change, though its funding has come from public sources and not carbon markets (Boucher 2015).

Market-based approaches, including PES, also have governance challenges. The incentive of direct payments only lasts as long as the payments last, and the risk of destructive action resuming when these payments ends is high. To avoid this, other investments are needed to sustain long-term commitments to conservation by communities, such as education, which requires ongoing financial support (Nicholls 2004). Also, multi-stakeholder involvement is not necessarily equitable under market-based schemes. Those who are credible threats to conservation are more likely to receive payments than those who are already non-destructive, and those who are landless or have insecure tenure are less likely to have access to payments (Wunder 2007). In addition, strictly market-based approaches are based singularly on the value of the resource(s) or ecosystem service(s) in question (Kinzig et al. 2011), and not able to address other governance objectives such as equity and poverty alleviation.

\section{What can FLR learn from conservation?}

One of the underlying governance challenges to managing forests is complexity. Berkes (2007) argues that ecosystems are vertically and horizontally complex, and that institutions to 
govern them must be as well. There is no a single universal approach to manage this complexity, and there is a need for pluralism to address a wide array of objectives, stakeholders, and knowledge systems across scales. Efforts to restore forest landscapes present especially complex governance challenges for two major reasons. First, the goal of restoration is arguably more complex than conservation, requiring interdisciplinary collaboration to identify solutions and more active engagement from all stakeholders to implement them. Second, with an emphasis on the landscape scale, restoration must involve a high diversity of stakeholders and also grapple with biophysical and land use heterogeneity.

\section{Innovative governance mechanisms for FLR}

In this special issue, we highlight examples of innovative governance for FLR. These include both new governance institutions that have supported landscape restoration in a given context, and examples where existing governance structures have been used in innovative ways to produce landscape-level forest restoration. The governance innovations described here include introducing new types of forest or land tenure systems that foster restoration; introducing new practices, technologies, or markets that make restoration more broadly appealing and accessible in a given context; facilitating collaborations between existing institutions that foster restoration efforts; and repackaging existing strategies to be more effective for restoration.

The articles in this special issue highlight governance interventions that span multiple scales, from changes in local rules and norms to multinational conservation agreements. Case reports from Tanzania, Brazilian Amazon, the Philippines, Ghana, Honduras, Mexico, Peru and Ecuador illustrate a number of innovations at the local level. Two draw lessons from less 
effective interventions: In Tanzania, Sungusia and Lund show how a government program focused on creating community reserves improved management and forest outcomes within reserves. But because the program's narrow focus neglected to take a holistic approach across the landscape, it created perverse incentives that led to leakage and deforestation elsewhere. Baruah et al. describe internal governance challenges within Community-Resource Management Areas, which include poor accountability and transparency, and how action learning can improve these issues to enable restoration.

Cases also illustrate the potential of future projects, or existing innovations that can be applied elsewhere. In Brazil, Newton et al. discuss the potential of a set of strategies commonly used to lift barriers to participating in restoration - although each intervention has often been used alone (with varying degrees of success), the innovation here is combining them to address multiple barriers to participating in restoration projects at one time, providing comprehensive support that can be locally adapted depending on which barrier is most problematic in a given context. In a study of community-based approaches to restoration in the Philippines, Cagalanan highlights the challenges that arise when restoration efforts are initiated by the state when the target communities do not have prior experience in community-based forest management. In this context, when the state may not have the resources necessary to organize, train, and motivate communities, strategic partnerships with private sector actors involved in reforestation may help achieve better outcomes.

Many local cases emphasized that governance frameworks must allow restoration to be adapted to local needs, and, in particular, to allow people to produce food in a variety of traditional or context-specific ways. Bray's case from Oaxaca, Mexico shows how communal control over land combined with appropriate government interventions and support led a 
community to combine traditional land use practice with strikingly sophisticated modern forestry methods. This arrangement ultimately produced highly functional community forest management arrangements that allow for use while conserving forests and producing traditional foods. Similarly, the case from Peru presented by Robiglio and Reyes states that agroforestry concessions can be a successful means of promoting landscape level reforestation - but only if they allow for traditional cultivation systems and alternative forms of agroforestry within the mosaic. A report by Kramer and Vallarino from Honduras shows that allowing space and time for community governance to evolve organically can not only create successful restoration projects with community support and tangible, needed benefits, but can also forge a 'social fabric' that can prepare communities to face other environmental challenges. They advocate for patience, careful listening and responding to needs, and adaptive management as principles to govern and support grassroots community restoration movements. In a similar vein, Wilson's case from the Ecuadorian Andes shows that introducing communal tenure create conditions that foster local participation, sharing, and support - if done with and for communities. It illustrates how designing restoration projects to directly meet local needs, providing space and flexibility for innovation, and engaging charismatic, well-trusted leaders to spearhead and lead projects, helped to fuel a grassroots 'regreening' movement across the landscape that extended well beyond the initial reserves established.

Case reports from regional and national levels reinforce several of the same key points all of the successful governance arrangements presented involve devolving rights or responsibilities to local communities and allowing local adaptations and innovations within a broader policy or framework. In a case from the Atlantic forests of Brazil, Brancalion et al. show that engaging stakeholders and providing shared platforms for problem solving allowed for local 
specificity. But it was combining these components with a harmonized vision for the region that both fostered local flexibility and inspired action to produce the intended end goals at a larger scale. In Guatemala, Hernandez et al. describe how successful restoration initiatives at a national level relied on providing a space for dialog between multiple levels of government (from local to national), incorporating local goals into a larger framework, and the creation of national laws to support restoration. Similarly, Mansourian et al. show that to meet Madagascar's ambitious reforestation goals engaging stakeholders across sectors and scales was key, as was creating locally relevant projects for communities. Zhang and Putzel explain how China's widespread reforestation was largely due to a national government approach that integrated and included multiple governing silos (i.e., agriculture, water, and forestry departments). In this case, increasing community autonomy to manage land combined with technological advances in finance to compensate landholders produced widespread, positive outcomes for restoration. In Germany, Boecher describes how a regional policy competition to initiate regional-level governance helped 'discover' regions with special promise for achieving multiple restoration goals, which served as a place to intiate restoration efforts and serve as examples for restoration projects elsewhere in the country, and internationally. Finally, at the multinational level, a study by Holder of the Trifinio Fraternidad Biosphere Reserve also shows the importance of connecting the local to the national, highlighting how active, sustained communication and participation between individuals in the governments of each participating country can create management that is both locally relevant and coherent at higher levels of government.

\section{Conclusion}


Taken together, these examples of governing restoration reveal several key lessons. First, at the local level, engaging stakeholders early in the process of project design is critical. This allows people a degree of ownership and control over the projects, and also allows projects to be tailored to local needs. A second and related lesson is that listening to local people - their needs and goals - and implementing projects in a way that meets these needs is crucial to foster motivation and support for projects. Several of the cases illustrate innovative ways that listening and sharing between levels of administration and stakeholders can be achieved. Third, there is no silver bullet with respect to the type of restoration implemented or the governance mechanism applied - different contexts will require different interventions depending on the needs of the local people who live there and the range of other stakeholders involved. Fourth, projects should allow traditional and culturally relevent practices to be incorperated, especially food production systems. Fifth, projects should have space to change and adapt over time as needs, goals, and environments change. Thus, for restoration to work, governance approaches must be peoplecentered, adaptable, context dependent, and engage people's motivations, ideas, and cultural norms and values. These lessons that apply at the local level also resonate regionally - although engaging a range of stakeholders and sectors across scales can be cumbersome and time consuming, it is important to produce projects that are both locally relevant but can meet the goals of regional, national, and international actors. Cases illustrate different platforms, models, and methods to achieve this cross-sectoral, multi-level engagement, but even regional, national and international cases highlight the importance of considering and involving local peoples.

\section{References}

Alpert, P. 1995. Applying Ecological Research at Integrated Conservation and Development Projects. Ecological Applications 5 (4). 
Berkes, F. 2007. Community-Based Conservation in a Globalized World. Proceedings of the National Academy of Sciences of the United States of America 104 (39):15188-15193.

Bhagwat, S. A., Willis, K. J., Birks, H. J. B., \& Whittaker, R. J. (2008). Agroforestry: a refuge for tropical biodiversity?. Trends in ecology \& evolution, 23(5), 261-267.

Boucher, D.H. 2015. The REDD/Carbon Market Offsets Debate: Big Argument, Small Potatoes. Journal of Sustainable Forestry 34: 547-558.

Chazdon, R. L., Brancalion, P. H., Laestadius, L., Bennett-Curry, A., Buckingham, K., Kumar, C., ... \& Wilson, S. J. (2016). When is a forest a forest? Forest concepts and definitions in the era of forest and landscape restoration. Ambio, 1-13.

Chazdon, R.L. 2015. Second Growth: The promise of tropical forest regeneration in an age of deforestation. The University of Chicago Press. Chicago, IL.

De Beenhouwer, M., Aerts, R., \& Honnay, O. (2013). A global meta-analysis of the biodiversity and ecosystem service benefits of coffee and cacao agroforestry. Agriculture, ecosystems \& environment, 175, 1-7.

Foley, J. A., C. Monfreda, N. Ramankutty, \& D. Zaks. (2007). Our share of the planetary pie. Proceedings of the National Academy of Sciences, 104, 12585-12586.

Foley, J. A., DeFries, R., Asner, G. P., Barford, C., Bonan, G., Carpenter, S. R., ... \& Helkowski, J. H. (2005). Global consequences of land use. Science, 309(5734), 570-574.

Joppa, L. N., \& Pfaff, A. (2009). High and far: biases in the location of protected areas. PloS one, 4(12), e8273.

Kinzig, A.P., C. Perrings, F.S. Chapin III, S. Polasky, V.K. Smith, D. Tilman, and B.L. Turner II. 2011. Paying for Ecosystem Services - Promise and Peril. Science 334: 603-604.

Laestadius, L., Buckingham, K., Maginnis, S. and Saint-Laurent, C., 2015. Before Bonn and beyond: the history and future of forest landscape restoration. Unasylva, 66(245), p.11.

Larson, A. M., D. Barry, and G. R. Dahal. 2010. New Rights for Forest-Based Communities? Understanding Processes of Forest Tenure Reform. International Forestry Review 12 (1):78-95.

Lewis, S.L., D. P. Edwards, and D. Galbraith. 2015. Increasing human dominance of tropical forests. Science 349: 827-832.

Maginnis, S. and Jackson, W., 2005. Balancing restoration and development. ITTO Tropical Forest Update, 15(2), pp.4-6.

MEA. 2005. Millennium Ecosystem Assessment: Ecosystems and Human Well-Being: Synthesis. Washington, D.C.: World Resources Institute.

Neumann, R. P. 2004. Nature-State-Territory: Toward a Critical Theorization of Conservation Enclosures. In Liberation Ecologies, eds. R. Peet and M. Watts. New York: Routledge.

Nichols, H. 2004. The Conservation Business. PLoS Biology 2(9): 1256-1259. 
Pattanayak, S.K., S. Wunder, and P.J. Ferraro. 2010. Show Me the Money: Do Payments Supply Environmental Services in Developing Countries? Review of Environmental Economics and Policy. Pp.1-21.

Ribot, J. C. 2004. Waiting for Democracy: the Politics of Choice in Natural Resource Decentralization. Washington, DC: World Resources Institute.

Rudel, T. K., Coomes, O. T., Moran, E., Achard, F., Angelsen, A., Xu, J., \& Lambin, E. (2005). Forest transitions: towards a global understanding of land use change. Global environmental change, 15, 23-31.

Sabogal, C., Besacier, C. and McGuire, D., 2015. Forest and landscape restoration: concepts, approaches and challenges for implementation.Unasylva, 66(245), p.3.

Sloan, S. (2008). Reforestation amidst deforestation: simultaneity and succession. Global Environmental Change, 18(3), 425-441.

Turner, R.K. and G.C. Daily. 2008. The Ecosystem Services Framework and Natural Capital Conservation. Environmental Resource Economics 39: 25-35.

Wunder, S. 2007. The Efficiency of Payments for Environmental Services in Tropical Conservation. Conservation Biology 21(1): 48-58. 